\title{
The effect of Educational Program of Breast Self Examination on Females' Employees 'Behavior
}

\author{
Om-Mohamed A. Abd Elsatar, \\ Hanan R. Attalla \\ Lecturer Adult Health Nursing Department, \\ Faculty of Nursing, Menofia University Egypt
}

\begin{abstract}
Breast cancer is the most frequently occurring cancer in women. One out of every 10 women have breast cancer in their lifetime and 1 out 3 have a risk of dying from breast cancer. The early diagnosis of breast cancer increases the rate of survival. Many tumors can be detected by the women herself by breast self-examination. Aim of the study: this study was carried out to evaluate the effect of Breast Self Examination educational program on knowledge, attitude and practice of female employees. Setting: This study was conducted in faculty of nursing Menoufia University and the old secondary school for girls in Menoufia governorate. Sample: A Convenient sample, consisted of (60) female employee and agree to participate in this study. Tools: two tools were utilized for data collection. 1. Interviewing Questionnaire. 2. Champion's Health Belief Model Scale (1997). The results revealed that there was a significant difference between before and after implementation of the educational program of breast self examination in relation to nurses' knowledge, attitude and practice of breast self examination. Conclusion: In the current study the researcher concluded that the implementation of the educational program of breast self examination was effective in improving females' knowledge, attitude and practice of breast self examination. Recommendation: An educational program about breast self examination should be designed for all women in any age groups and presented in mass media.
\end{abstract}

Key words: Breast, examination, attitude, knowledge and practice. 


\section{Introduction:}

Breast cancer is the most common cause of cancer-related deaths among women worldwide (1). The incidence of breast cancer varies between countries; A high prevalence rate of breast cancer is noted among women living in Denmark, Finland and Sweden ${ }^{(2)}$. In Egypt, breast cancer is the most common cancer among women, representing $18.9 \%$ of total cancer cases $35.1 \%$ in women and $2.2 \%$ in men. Statistical records of the Egyptian National Cancer Institute illustrates 180.000 annual cases of breast cancer occurs during the year $2001{ }^{(3)}$ : Breast cancer is the most prevalent cancer among Egyptian women and constitutes $29 \%$ of National Cancer Institute cases ${ }^{(4) \text {. }}$

The risk of breast cancer increases with age. Being over the age of 50 also increased a woman's risk for breast cancer (5). The primary factors that increase risk of breast cancer in women include certain inherited genetic mutations, a personal or family history of breast cancer, and biopsyconfirmed hyperplasia (6). Other factors that increase breast cancer risks include a long menstrual history (menstrual periods that started early and/or ended late in life), obesity after menopause, recent use of oral contraceptives, postmenopausal hormone therapy, never are having had children or having the first child after age 30, ethnicity characteristics, exposure to radiation, or consumption of one or more alcoholic

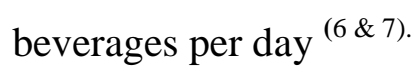

Early detection of breast cancer plays an important role in reducing its morbidity and mortality. Theoretically, a 95\% survival rate could be achieved if this cancer was diagnosed at an early stage ${ }^{(8)}$. In fact, $90 \%$ of masses in breasts are detected by the women themselves and $25 \%$ of have been found to have been malignant. Because of this women must be informed and their awareness raised about the risks of breast cancer, its symptoms and about breast self examination ${ }^{(9,10,11,12) .}$ BSE, mammography, and clinical breast examination are considered as screening methods for early detection of breast cancer ${ }^{(13) .}$ Although there is controversy surrounding the efficacy of BSE in countries where mammography and clinical breast exams are readily available, elsewhere BSE remains a cost-effective method to detect breast cancer. A woman who performs regular BSE may be more 
motivated to seek medical attention, including mammography and clinical breast exams if available ${ }^{(14) .}$

Despite the relative benefits of BSE, its application remains low (15). Studies conducted among different groups of women in United States, showed that monthly BSE rates ranged from $29 \%$ to $63 \%{ }^{(16)}$. A study conducted in Nigeria revealed that only $18.1 \%$ of participants reported regular application of BSE ${ }^{(17) .}$ Similar results were found among Iranian women with only $17 \%$ conducting regular BSEs ${ }^{(18) .}$ Variables such as demographic characteristics, knowledge, and education influence the practice of BSE (17). Furthermore, a lack of belief regarding the necessity of regular BSE has an impact on the engagement of this screening behavior. Understanding women's beliefs regarding BSE can be used to design appropriate educational interventions which promote screening behavior ${ }^{(13) \text {. }}$

A pictorial example of breast selfexamination in six steps. Steps 1-3 involve inspection of the breast with the arms hanging next to the body, behind the head and in the side. Step 4 is palpation of the breast. Step 5 is palpation of the nipple. Step 6 is palpation of the breast while lying down. ${ }^{(19) .}$
The Health Belief Model (HBM) is a psychosocial model that accounts for health behaviors by identifying factors associated with individuals' beliefs which influence their behaviors ${ }^{(20) .}$ According to this model, individuals who perceive themselves as susceptible to a certain disease (perceived susceptibility), who perceive that the disease has potentially serious consequences (perceived severity), who believe that preventive actions will cause positive outcomes (perceived benefits), who perceive that barriers to taking preventive actions are outweighed by the benefits, and who believe that they are able to engage in a certain preventive health behavior (self-efficacy), are more likely to engage in that health behavior ${ }^{(8)}$. This model has been widely used to examine beliefs related to breast cancer screening behaviors such as BSE ${ }^{(13) .}$

\section{Aim of the study:}

The aim of the present study was to evaluate the effect of Breast Self Examination educational program on knowledge, attitude and practice of female employees

Research hypothesis: The following research hypotheses were formulated in an attempt to fulfill the purpose of the study: 
1. Females employee attending breast self examination educational program with higher mean knowledge scoring post intervention than those of pre intervention

2. Females employee attending breast self examination educational program with higher mean attitude scoring post intervention than those of pre intervention

3. Females employee attending breast self examination educational program with higher mean practice scoring post intervention than those of pre intervention

\section{Operational definition:}

Employees' behavior in this research refer to woman's knowledge, attitude and practice of breast self examination

\section{Research design:}

Quasi experimental research was utilized in this study. It based on pre test -post test model, involve the manipulation of independent variable but there is no control group

\section{Setting:}

This study was conducted at faculty of nursing Menoufia University and the old secondary school for girls in Menoufia governorate. Egypt. The data was gathered from October 2010 to May 2011

\section{Subjects:}

A Convenient sample, consisted of (60) female employee and agree to participate in this study they were selected according to the following criteria:

1. Age: ranged from 18 years to 40 years

2. Working female

3. Not suffer from cancer before

4. Have no disability to perform breast self examination (handicapped).

In this study, BSE was the dependent variable

\section{Tools:}

For the purpose of the study and to collect the necessary data two tools were utilized by the researcher which was designed in line with the relevant literature.

Tool I: Interviewing Questionnaire: was developed by the researcher it include 4 parts:

PartI:Socio-demographic characteristics: Demographic data (age, marital status, education) were obtained in this section.

Part II: knowledge regarding breast self examination interview questionnaire sheet: The questions intended to measure knowledge about Breast Self Examination, 
the score was done through 15 questions, each item was scored as 4 correct answer, 3 incomplete answer, 2 wrong answer, and 1 don't know answer. The range of score was from 15 to 60 . The researcher considered knowledge score less than 60\% $(60 \times 60 \div 100=36$ degree $)$ unsatisfactory knowledge while 60\% (36 degree) and more considered satisfactory knowledge.

Part III: Observational Checklist of Breast Self Examination practice: this tool was used to observe technique of breast self examination, the practice score was done through 6 questions. Each question was scored as 3 for correctly done, 2 for correct to some extent, and 1 for incorrect or not done. The range of score was from 6 to 18 . The researcher considered practice score less than $60 \%(60 \times 18 \div 100=10.8$ degree ) incorrect practice while $60 \%$ (10.8) and more considered correct practice

Part IV: Breast Self Examination attitude: the attitude of the participant toward BSE and questions relating to practices of Breast Self Examination as Do you think BSE necessary? Have you done BSE before? The total score ranged from 14 to 70. We scored the items on a 5-point Likert scale ranging from strongly agree to strongly disagree, agree, not decided and disagree responses gained 5,4,3,2, and 1 scores, respectively. The researcher considered attitude score less than 60\% (60 $\times 70 \div 100=42$ degree ) negative attitude while $60 \%$ (42) and more considered positive attitude.

\section{Tool Tow: Champion's Health Belief} Model Scale (1997). This instrument measures HBM variables related to the performance of BSE, the concepts of disease susceptibility (5 items), seriousness (7 items), benefits (6 items), barriers (6 items), self-efficacy (11 items) and health motives (7items). The original scales were tested and found to be valid and reliable for measuring BSE practice and breast cancer beliefs. We scored the items on a 3point Likert scale ranging from agree to disagree; agree, not decided and disagree responses gained 3, 2, and 1 scores, respectively. Prior to data collection, the CHBS was translated into Arabic language. Then it was back-translated into 
English. Minor translation adjustments were carried out until the two versions (Arabic/English formats) were identical.

\section{Method:}

This research was carried out on 2 phases (preparatory, implementation and evaluation phases):

\section{Preparatory phase: this phase include:}

a- Tools were developed and tested for Content validity by 5 expertises from medical surgical nursing and medical staff members department from Menoufyia University.

b- Reliability: Every question in each study tool was tested for reliability (testretest reliability with $r=0.88$ ). This was performed by asking twice so as to compare the consistency of answers produced for the same question by the same respondent.

c- Seeking an official letters describing the purpose and significance of the present study was obtained.

d- A pilot study was conducted on 5 working females at Menoufyia Governerate and those were excluded from the current study.

\section{II-Implementation and evaluation phase}

1. A structured interview was utilized in order to fill out the study tool I and II.
The interview was conducted by introducing the researcher herself to the working females and giving them simple explanation about the aim of the study and assured them information will be confidential and will be used only for the purpose of study. An oral consent was obtained to participate in the study from each subject.

2. An observation technique was utilized to fill out study tool I part III. [The interview and observation take one month to identify subjects' knowledge, attitude and practice of breast self examination (pre-intervention)].

3. Educational program of breast self examination was given on a short sessions of about 30-60 minutes. The researcher divided the sample (60) into 12 groups, each group include 5 employees. It took 2 sessions for each group to acquire the needed knowledge and training on BSE practice. Each group was given intensive theoretical and practical session in BSE. The theoretical part of the program presented in 1 session as lecture and discussion followed by the second part which consist of one 
session for practice as demonstration and re demonstration. The theoretical part include definition, causes, manifestation of breast cancer, action taken when discovered any breast abnormalities, risky age, types of breast mass, methods of diagnosis, treatment, prevention of breast cancer, importance of breast self examination, mammography instructions, best time to do BSE and how many times to do it, signs to examine for, and steps of BSE. The practical part of breast self examination includes 6 steps. Steps 13 involve inspection of the breast with the arms hanging next to the body, behind the head and in the side. Step 4 is palpation of the breast while standing. Step 5 is palpation of the nipple. Step 6 is palpation of the breast while lying down. While standing, raise your left arm. Using your right hand and beginning at the outer edge of the breast, press the flat part of the fingers in small circles, moving slowly around your breast and towards the nipple. Give attention also to the area between your underarm and breast. Lying flat, position a pillow under your left shoulder, and place the left arm over or behind your head. Use the same circular motion as described earlier. Repeat the procedure for the right side. Gently squeeze your nipples to check for any discharge. Carry out the same procedure for the right breast.

4. The researcher gave verbal and written instruction (booklet) for each patient. The researcher based on review of literatures, results and recommendations of previous researches designed the instruction hand out

5. An immediate post-test was carried out after providing the needed interventions. Each subject was evaluated using tool I and II to estimate the improvement of subjects' knowledge attitude and practice of BSE. This take one month.

6. Each subject was evaluated after 3 month using tool II and III (follow up test). This take one month.

\section{Statistical analysis}

Upon completion of data collection, each variable in the study tools was manually scored. Computerized data entry and statistical analysis were fulfilled using the statistical package for social sciences 
(SPSS). Descriptive statistics were first applied (e.g., frequency, percentage, mean and standard deviation). Tests of significance were used to compare study group using chi square test, P- values, which were less than 0.05 , were considered as statistically significant.

\section{Results:}

Table (1) showed that the respondents' ages ranged from 23-50 years and their mean age $33.93 \pm 6.71$, around half of them were single (46.7\%), and the majority had secondary level of education (81.7\%).

Table (2) showed that the prevalence of satisfactory knowledge, positive attitude and correct practice is significantly higher among post intervention than pre and follow up intervention among studied group ( $\mathrm{p}<0.001)$.

Table (3) showed that mean value of knowledge, attitude, and practice (KAP) among post intervention is significantly higher than pre and follow up intervention among studied group $(\mathrm{p}<0.001)$.

Table (4) showed that the Mean value of health belief model is significantly higher among post intervention than pre and follow up intervention of studied group $(\mathrm{p}>0.05)$.
Table (5) showed that there is non significant positive correlation between knowledge and both practice and attitude among pre, post and follow up intervention among studied group ( $p>0.05$ ).

Table (6) showed that there is significant positive correlation between practice and attitude among pre, post and follow up intervention among studied group (p>0.001). 
Table (1): Number and percentage distribution of socio demographic data of studied $\operatorname{group}(\mathbf{n}=60$

\begin{tabular}{|c|lc|}
\hline Demographic data & No & $\%$ \\
\hline Education level: & & \\
- Illiterate & 2 & 3.3 \\
- Read and write & 3 & 5.0 \\
- Primary & 6 & 10.0 \\
- secondary & 49 & 81.7 \\
\hline Marital state: & & 46.7 \\
- Single & 28 & 45.0 \\
- Married & 27 & 3.3 \\
- Widow & 2 & 5.0 \\
\hline Age in years (mean \pm SD) & 3 & \\
\hline Range & $33.93 \pm 6.71$ & \\
\hline
\end{tabular}


Table (2): Comparison between Pre, Post and Follow up regarding (KAP) Knowledge, Attitude and Practice of Studied Group

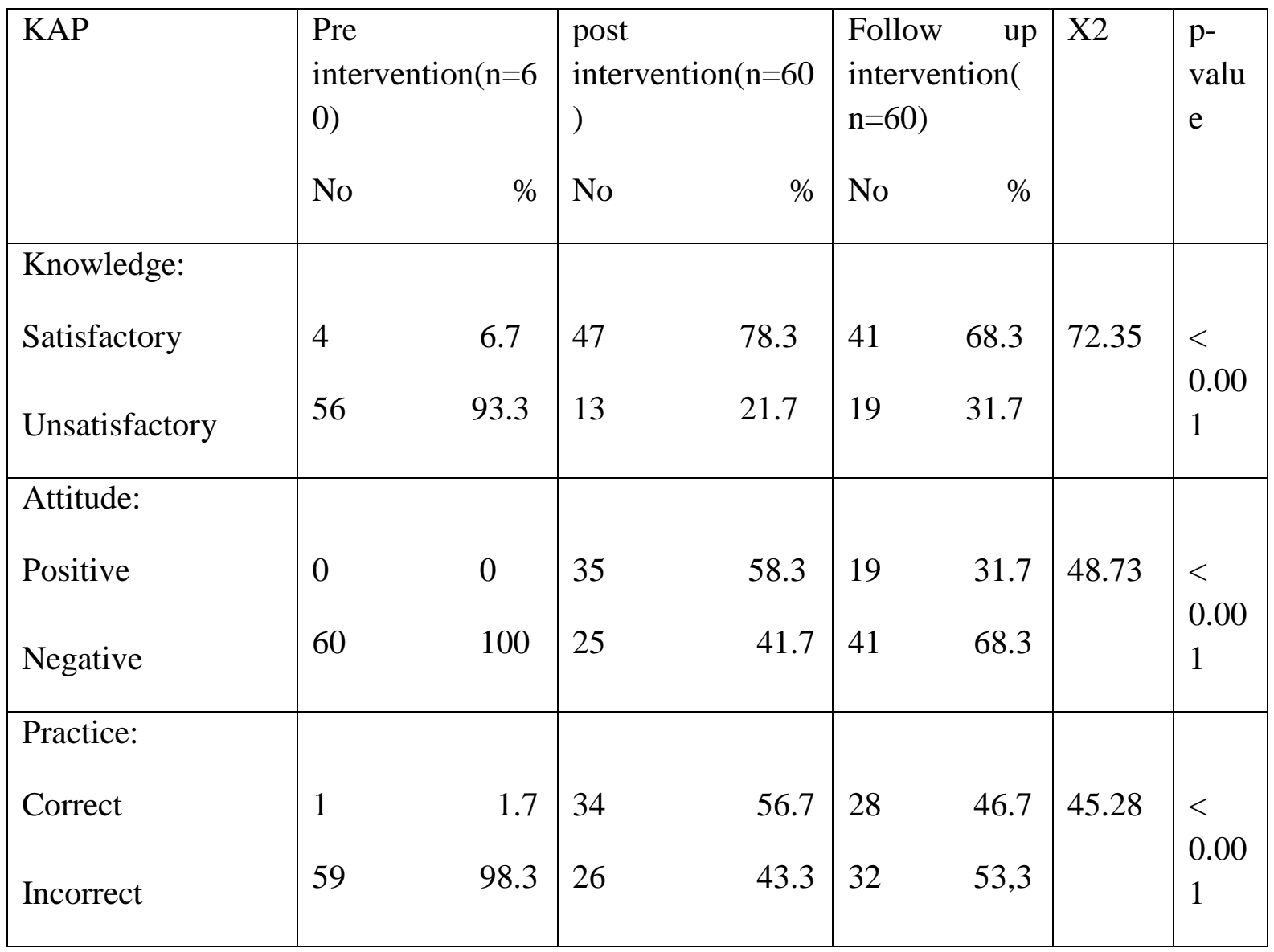


Table (3): Comparison between Pre, Post and Follow up regarding mean score of knowledge, attitude and practice

\begin{tabular}{|c|c|c|c|c|c|}
\hline Variable & $\begin{array}{l}\text { Pre } \\
\text { intervention } \\
(\mathrm{n}=60) \\
-\mathrm{x} \pm \mathrm{SD}\end{array}$ & $\begin{array}{l}\text { Post } \\
\text { intervention } \\
(\mathrm{n}=60) \\
-\mathrm{x} \pm \mathrm{SD}\end{array}$ & $\begin{array}{l}\text { Follow up intervention } \\
(\mathrm{n}=60) \\
-\mathrm{x} \pm \mathrm{SD}\end{array}$ & f-test & p-value \\
\hline Knowledge & $34.15 \pm 4.63$ & $46 \pm 6.34$ & $43.73 \pm 6.88$ & 65.36 & $<_{0.001}$ \\
\hline Attitude & $52.15 \pm 4.74$ & $69.98 \pm 16.05$ & $65.57 \pm 13.19$ & 34.19 & $<0.001$ \\
\hline Practice & $9.18 \pm 1.23$ & $12.8 \pm 2.28$ & $11.73 \pm 1.89$ & 60.69 & $<0.001$ \\
\hline
\end{tabular}

$\mathrm{P} 1=$ between pre \&post $\quad \mathrm{P} 2=$ between pre \&follow up $\quad \mathrm{P} 3=$ between post $\&$ follow up 
Table (4): comparison between pre, post and follow up intervention regarding mean score of health belief model

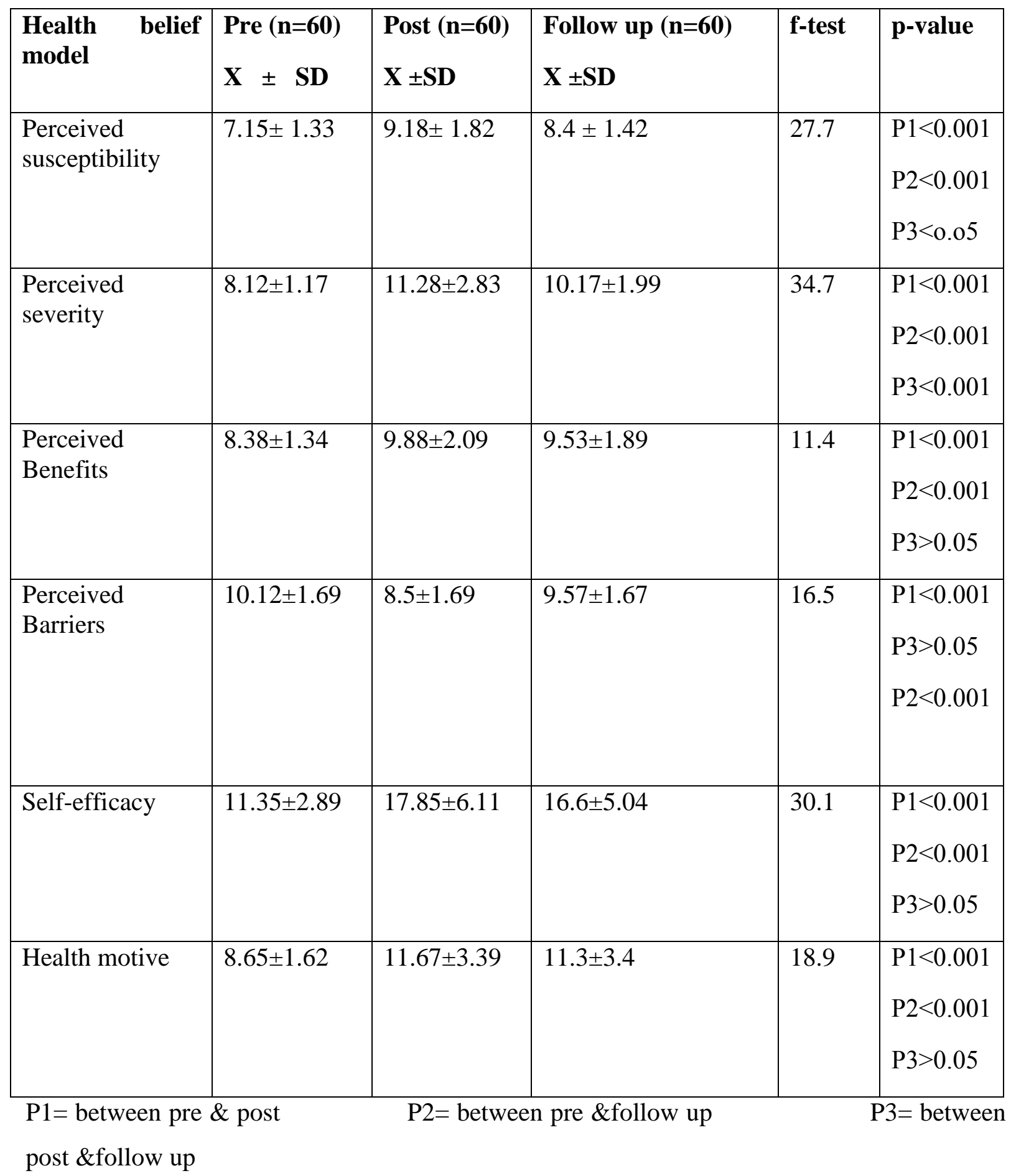


Table (5) Pearson correlation between knowledge and both practice $\&$ attitude

\begin{tabular}{|l|l|l|l|l|l|l|}
\hline Parameter & \multicolumn{2}{|l|}{ Pre(n=60) knowledge } & \multicolumn{2}{l|}{ Post(n=60) knowledge } & \multicolumn{2}{l|}{$\begin{array}{l}\text { Follow } \\
\text { knowledge }\end{array}$} \\
\cline { 2 - 7 } & R & p-value & R & p-value & R & p-value \\
\hline Practice & 0.21 & $>0.05$ & 0.11 & $>0.05$ & 0.1 & $>0.05$ \\
\hline Attitude & -0.01 & $>0.05$ & 0.14 & $>0.05$ & 0.11 & $>0.05$ \\
\hline
\end{tabular}

Table (6) Pearson correlation between practice $\&$ attitude

\begin{tabular}{|l|l|l|l|l|l|l|}
\hline Parameter & \multicolumn{2}{|l|}{ Pre(n=60) practice } & \multicolumn{2}{|l|}{ Post(n=60) practice } & \multicolumn{2}{l|}{$\begin{array}{l}\text { Follow } \\
\text { practice }\end{array}$} \\
\cline { 2 - 7 } & R & p-value & R & p-value & R & p-value \\
\hline Attitude & -0.02 & $>0.05$ & 0.79 & $>0.001$ & 0.62 & $>0.001$ \\
\hline
\end{tabular}




\section{DISCUSSION:}

Breast self-examination remains the most controversial of commonly recommended procedures for breast cancer screening. The rationale behind expanding BSE use as a screening mechanism stems from the fact that breast cancer is frequently detected by women themselves without any other symptoms. Although BSE is simple, noninvasive, and inexpensive, its effectiveness is heavily debated in spite of more than 30 years of research ${ }^{(21,22,23)}$.

With respect to the socio-demographic characteristics of the subjects, this study noticed that the respondents ages ranged from 23-50 years and there mean age 33.93 \pm 6.17 ; around half of them were single and the majority had secondary level education in contrast to this finding,( 24) who reported that the ages of women ranged from 20- 64 years and their mean age was $37.7 \pm 13.7 ; 67.6 \%$ were married and $49.2 \%$ were primary school graduates.

As regard to participants' satisfactory knowledge the finding of the current study showed that, there was a statistical significant difference between pre-program and post-program that indicates an improvement of participants' total means score of knowledge post-program. These findings are in accordance with, (25) who assured that there was a statistically significant difference between pre and post-education mean scores in the students' breast self examination knowledge acquisition. This finding is consistent also with a number of previous studies that have demonstrated a positive effect and improvement of training programs of subject's knowledge (26 \&27).

This result was also matching with (28) reported that teaching sessions provided to study subjects increased the patient's knowledge. This result was also in agreement with that of (29) showed significant differences before and after conducting the program that indicates an improvement of the patients mean total scores after the intervention.

Concerning the participants' positive attitudes to breast self examination, the result of the current study display that, there was a statistical significant difference between pre-program and post-program that indicates an improvement of participants' positive attitude. This finding agrees with ${ }^{(30)}$ who highlighted that a 
relative improvement was observed in those who had positive attitude after the program, in comparison to pre-program.

Regarding champion health believes models; the current study revealed statistical significant increase in mean scores of perceived benefits and significant decrease in perceived barriers after the program. These findings agree with (31) who found that there was an increase in perceived benefits and a decrease in barriers in both peer and group education. In this study there was statistical significant increase in mean scores of perceived susceptibility, perceived severity and health motive. These findings disagree with ${ }^{(31)}$ who reported that there was no change in susceptibility, perceived seriousness and health motivation.

The present study showed increase in mean scores of self-efficacy these finding consistent with $^{(32)}$ who stated that education program could enhance perceived self efficacy on breast self examination practice.

The current study revealed that there was significant positive correlation between practice and attitude among pre, post and follow up intervention. These results were on line to some extend with ${ }^{(33)}$ who stated that the individual's attitude about the breast self examination benefits is related to performing breast self examination.

This study showed that there is non significant positive correlation between knowledge and both practice and attitude among pre, post, and follow up intervention group. This result was in contrast with ${ }^{(34)}$ who concluded that the most common reason for not doing breast self examination was lack of knowledge besides, there was statistically significant correlation between age, occupation, knowledge and women's practices. Another study that was carried out on 382 health care professional women in Iran aged 20 to 64 years mentioned that the majority had good knowledge and attitudes, but had poor practices regarding breast cancer early detection. ${ }^{(35)}$

Conclusion: In the current study the researcher concluded that the implementation of the educational program of breast self examination was effective in improving females' knowledge, attitude and practice of breast self examination.

\section{Recommendation:}

1. An educational program about breast self examination should be designed for all women in any age groups and 
for women's health promotion from puberty to post-menopause.

2. Mass media could efficiently be utilized to present specific programs associated with breast self examination to disseminate a healthy positive attitude toward breast self examination.

3. It would be best to start educating women performing regular breast self examination in early adulthood so that this becomes their habitual behavior.

\section{References:}

1. Jemal A, Siegel R, Ward E, Murray T, Xu J, Smigal C, Thun MJ. Cancer statistics .CA: A Cancer J Clin ,2006; 56(2):106-130.

2. Rostgaard K, Vaeth M, Holst H, Madsen M, Lynge E. Age-periodcohort modeling of breast cancer incidence in the Nordic countries. Stat Med,2001; 20(1):47-61.

3. Elatar, I., Cancer registration, National Cancer Institute, Available at: http://www.nci.edu.eg/journal/nci2001

4. Omar, S., Khaled, H., Gaafar, R., Zekry, A., Eissa, S., and El - Khatib, O. Breast cancer in Egypt: A review of disease presentation and detection strategies. Eastern Mediterranean health journal, 2003;9 (3): 448 -63.
5. Abd Elalem.S.M,. Effect of Stress on Immune Responses after Surgical Treatment of Breast Cancer, Master thesis, faculty of nursing, Menofia university. 2008

6. American Cancer Society. Cancer Facts and Figures [http://www.cancer.org/]2005

7. Lee EO, Ahn SH, You DS, Han W, Choe KJ, Noh DY. Determining the main risk factors and high-risk groups of breast cancer using a predictive model for breast cancer risk assessment in South Korea. Cancer Nursing ,2004; 27:400-406.

8. Yarbrough SS, Braden CJ. Utility of health belief model as a guide for explaining or predicting breast cancer screening behaviors. J Adv Nurs ,2001; 33:677-88.

9. Şen S, Öztürk M, Kişioğlu AN. "Level of Knowledge of Females in Isparta of the 25-65 Year Age Group concerning Risk Factors and Symptoms of Breast Cancer", VIII th National Congress for Public Health].2002

10. Parlar S, Bozkurt AI, Ovayolu N. The evaluation of the education about the breast cancer and breast selfexamination given to women applying 
to Child and Mother Health Centre. Journal of Cumhuriyet University School of Nursing.2004;8(2):9-15

11. Koçoğlu F, Özbayır T. Investigation of the Level of Knowledge of Students Residing in the Bornova Dormitory of the Loans and Dormitories Agency concerning Breast Cancer and Breast Self-Examination, 3rd International, 10th National Congress of Nursing], İzmir (Poster presentation). 2005

12. Kılıç S, Uçar M, Seymen E, İnce $S$, Ergüvenli Ö. Investigation of Knowledge and Practices of assigned nurses, nursing students and female patients which present to the GATA Training Hospital concerning Breast Self-Examination, Gülhane Medical Journal],2006; 48: 200-204

13. Avci I.A. Factors associated with breast self-examination practices and beliefs in female workers at a Muslim community. Eur J Oncol Nurs ,2008; 12(2):127-133

14. Gozum. S, Aydin. I. Validation evidence for Turkish adaptation of Champion's health belief model scales. Cancer Nurs ,2004; 27(6):491-498

15. Canbulat.N.O. Health beliefs and breast cancer screening behaviors among female health workers in Turkey. Eur J Oncol Nurs,2008; 12:148-156.

16. Tavafian, s. s. et al . Prediction of breast self-examination in a sample of Iranian women: an application of the Health Belief Model. BMC Women's Health 2009, 9(37): pp 263-271

17. Balogun, M.O, Owoaje, E.T. Knowledge and practice of breast selfexamination among female traders in Ibadan, Nigeria. Annals of Ibadan Postgraduate Medicine, 2005;3(2):5256.

18. Montazeri.A,Vahdaninia.M, Harirchi.I, Harirchi.A, Sajadian.A, Khaleghi.F, Ebrahimi.M, Haghighat.S and Jarvandi.S. Breast cancer in Iran: need for greater women awareness of warning signs and effective screening methods. Asia Pacific Family Medicine ,2008; 7:6

19. Kösters, J.P, Gøtzsche, P.C. Regular self-examination or clinical examination for early detection of breast cancer. Cochrane Database of Systematic Reviews, Issue 4. Art. No.: CD003373.DOI:10.1002/14651858.CD 003373, 2007 
20. Champion VL, Scott CR. Reliability and validity of breast cancer screening belief scales in African American women. Nurs Res, 1997; 46(6):331337.

21. Baxter, N. Preventive health care, 2001 update: should women be routinely taught breast self examination to screen for breast cancer? Canadian Medical Association Journal, 2001;164, 18371846.

22. Miller, a. B. \& Baines, c. Self examination contributes to reduction in mortality. British Medical Journal Letter,2001; 322, 792.

23. Spurgeon, d. Breast self-examination may do more harm than good. British Medical Journal Letter,2001; 323, 11

24. Dundar, p. e. et al . The knowledge and attitudes of breast self-examination and mammography in a group of women in a rural area in western turkey. BMC cancer,2006; 24(6) 43.

25. Beydag, k. d. \& karaoglan, h. Effect of breast self examination education to the knowledge and attitudes of female students. ScopeMed journal ,2007; 6(2): 106-111

26. Eid, N.M. Nursing care planning a mean for achieving quality of health services at Shebin El-Kom University Hospital .PHD Thesis. Faculty of Nursing, University of Menoufiya, Egypt.2003; 56.

27. El Dahshan, M. E. A. The impact of a quality improvement program for nurses on the quality of nursing care rendered in Menoufiya University Hospital. Thesis of Dr of Nursing .Faculty of Nursing, University of Menoufiya. Egypt.2005; 140

28. El-Hefnawy, k. a. Impact of performing breathing and coughing exercise on prevention \& reduction of bronchial asthma complication among adults' asthmatics in Shebien El-koom Hospitals, MSC. Thesis, Faculty of Nursing , Menofia university,2003; 100

29. Fareed, M. E. Dietary management in chronic renal failure patients and its effect on nutritional status, renal function tests and serum electrolytes, DSC. Theses, faculty of nursing , Menofia university,2004; 100 
30. Karayurt, O., Dicle, A.\& Malak, A.T., Effect of peer and group Education on Knowledge, Beliefs and breast selfExamination practice among university students in Turkey. Turk J Med Sci. 2009;39(1): 59-66.

31. Ahmad F, Cameron JI, Stewart DE. A tailored intervention to promote breast cancer screening among south Asian immigrant women. Soc Sci Med ,2005; 60(3):.575-86.

32. Moodi.m, mood.m.b, sharifirad.g.r, shahnazi.h, and sharifzadeh.g. Evaluation of breast self examination program using health belief model in female students. JRMS, 2011; 16(3): 316-322
33. Parisa, p. \& Kandiah, M. Breast cancer knowledge, perception and breast selfexamination practices among Iranian women. The international Medical Journal,2005; 4(2). Pp: 17-24.

34. Ebrahimi, M., Hollakoi K. \& Rahimi A - Knowledge, attitude and practice regarding breast cancer among health professionals. Urmia Medical J.2001; 1 300-3002. 